The Geneva Papers on Risk and Insurance, 23 (No. 87, April 1998), 178-181

\title{
Comments on the Appeal of the Circumstances Clause and the Uninsurability of Long Tail Risks
}

\author{
by Gerhard Wagner, LL.M.*
}

The authors have presented us with a succinct and interesting analysis of the actuarial problems posed by long tail liabilities.

In the face of supposedly new and very substantial long tail liabilities, especially of the products and environmental liabilities nature, insurers throughout Europe and the United States have reacted by shifting the definition of the insurer's obligation from an earlier moment like "act committed" or "loss occurred" to a later point in time, like "damage discovered" or "claims made". This change in insurance policies creates an additional risk for the insured because it may turn out that the insurance he bought is useless. If I buy a claims made policy today and terminate it tommorow because I wind up my business, a claim which is filed against me the day after tommorrow based on a tort committed today will not be covered because my policy has expired. Given that the social function of third party insurance is to encourage beneficial but risky activities which would not be performed if the potential tort feasor had to bear the costs of damages by himself the factual exclusion of long tail liabilities reduces the incentive to engage in such risky activities in the first place. As one consequence of this effect, the potential actor might eschew the undertaking of risky activities altogether - or, if the mitigation of his incentive to do so is not strong enough, they provide the producer or service provider with a strong incentive to avoid the risk of uncovered long tails by avoiding to switch insurers. Thus, a definition of the insurers obligations' trigger close to the present, i.e. "damage discovered" or "claims made" policies, reduces competition in the insurance market. The Circumstances Clause promoted by the authors provides an effective cure for that problem because it creates a solid bridge between two successive insurance policies and thus

* University of Goettingen, Germany. 
enables the insured to switch insurers without incurring additional liability within the uncovered run off period.

Although this beneficial effect goes undisputed, I think the authors have shown us only one view of the cathedral.

(1) First of all, the paper does not mention the potential benefits to the insured of claims made policies and is silent about the drawbacks of act committed policies, respectively. Essentially, what a claims made policy is missing "at the end", the act commited type of insurance contract is missing "up front". If I buy an act committed policy today and a claim is filed against me tommorrow for a tort committed yesterday I stand without cover. More important, my long tail risks are covered not by modern policies with the high coverage I can afford today but by old policies which contain low ceilings unadjusted for the inflation rate of the many years which have passed since the policy was written and the tortious act was committed. To give a practical example, in the case of German standard insurance policies covering the risks associated with the pollution of ground and surface waters it proved very detrimental to the interest of the insured to deal with current claims on the basis of policies written in the sixties which provided coverage adequate to the standards and expressed in D-Marks of that time.

(2) My second and main point, however, is that the authors fail to recognize that the choice of trigger is neither just a question of convenience and expediency nor a means for the insurer to trap the insured by disappointing his "legitimate pre-legal expectations", but an important device for risk management which is essential to the functioning of insurance markets in difficult areas like products and environmental liability insurance. To be sure, I agree with the authors of the paper that long tail risks do not pose unsurmountable problems of insurability. To a large extent, the question of insurabiltiy is a matter of price, which in turn is a function of the risk-management capacities of the insurer. If the insured is willing to pay an appropriate price, any risk is insurable. In the real world, however, the insurer has to bargain for an appropriate price facing competition from other insurers and the myopia of insureds. In this situation the insurance industry may have no choice other than to resort to techniques of risk management which result in a severe - and deplorable - restriction of the scope of cover. The circumstances clause advocated by the authors counteracts these attempts to a certain degree because it forces the insurer to extend cover for a longer time period than it is willing to, and to grant the cover for the run-off period at zero price. What kind of rammifications does this have for the insurability problem?

Although insurance lines with a high propensity for long tail liabilities like products and toxic torts do not pose prohibitive problems for insurability, it should be out of the question that they present the insurer with serious difficulties concerning predictability and calculatability thus deserving the special attention of the insurer, i.e. efforts of risk management. One such device to mitigate the insurability problems of long tail risks is to choose an up-to-date trigger which allows for expedient adjustment of premiums in case it turns out that the risk of long tail liabilities was underestimated up front. The circumstances clause forces the insurer to stay in the risk without compensation and thus partly defeats its efforts at risk management. In a similar vein but more important the informational asymmetries between the two parties and the insurance contract are especially severe if the risks are latent in nature such as with long tail risks. It is clear that 
chosing an appropriate trigger is not the only means of coping with latent risks. It is, however, an important one. The choice of a trigger close or identical to the filing of the complaint enables the insurer to terminate the insurance policy if the risk assessment he has done ex ante proves to be wrong ex post. Although the same move is possible under an act committed policy termination of the insurance contract will only be of little benefit to the insurer because he has to compensate victims of all tortious acts which were committed before termination of the insurance contract. Thus, the long tail sticks with the insurer and cannot be cut off effectively. The knowledge of both parties that the insurer may easily discharge further obligations if his risk assessment turns out to be at fault provides the insured with a strong incentive (1) to disclose available information pertinent to the truthful assessment of the risk and (2) to monitor and control his own activities in order to avoid a series of severe long tail liabilities in the first place. Given that, it comes at no surprise that the German insurance industry explained its shift away from loss-occurance policies and towards the even more up-to-date trigger of discovery of losses in the sector of environmental liability insurance by pointing at the fact that the new trigger supplies the insurer with an instrument to cut off long tails effectively.

It is undisputable that the possibility of the insurer to effectively cut off long tail risks when the first of a series of similar losses materializes, in part devalues the benefit of insurance to the insured. But, contrary to the insinuation of the authors, that does not mean that society suffers a real loss. Perhaps their argument in terms of the social "function" of insurance has concealed to them that insurance provides society with benefits - but with costs as well. The most important potential social cost of third party insurance is the well known problem of moral hazard. Because an insurance contract effectively shifts risks of liability from the insured to the insurer, the incentive to make efforts at accident avoidance which is provided by ordinary tort law is weakened. The insured will no longer choose the efficient level of care, where the marginal cost of an additional unit of care equals the expected value of the damages to be avoided. To be sure, there are many ways for the insurer to counterbattle that danger. In case of long tail risks one important means to do so is to choose a trigger which assures the possibility of termination in case of unexpected losses. To the extent that the choice of trigger and the exclusion of coverage for run off periods reduce the risks of moral hazard, they are to be welcomed.

The same analysis applies to the problem of adverse selection. The power of the insurer to terminate the insurance contract at the beginning of a series of losses increases the probability for high-risk insureds of having to eat losses themselves rather than shifting them to their insurers. By increasing the costs of insurance for high-risk insureds only, a claims made or similar trigger helps to keep low-risk insureds within the insurance pool and thus makes it easier for the carrier to aggregate homogenous but independent risks. In short, the possibility to cut off long tail liabilities may be an important prerequisite for the functioning of insurance markets which is hampered by adoption of the circumstances clause.

Finally, the circumstances clause poses a serious technical problem. Its effectiveness, depends to a large extent, on what counts as a "circumstance". The choice of a broad definition would force the first insurer to stay in the risk even when the insured provides only rough data about future losses. With respect to environmental risks, one could think of a circumstances clause which is satisfied by communicating data about the substances 
emitted into air, water and soil, and by pointing out the then-known dangers of these substances. If that were the proper reading of the circumstances clause, the claims made trigger would be of little help to the insurer even compared to an act committed policy because the insured could easily extend his own cover at the end of the insurance period. On the other hand, if the term "circumstance" is defined narrowly, the clause will be of little help to the insured because the very problem of long tail is that they are latent in nature. It is not at all clear that the insured will be able to point out circumstances in the strict sense of the term at the end of the insurance period. To the extent that he is not able to do so, the circumstances clause does not improve the disadvantages of the claims made trigger.

Given that background, it might be preferable to both parties in the insurance contract to avoid the ambiguities of the circumstances clause altogether by employing a different device dealing with the problem of uncovered run-off periods. The new standard terms for the insurance of environmental liability in Germany, for instance, include a sunset-clause which provides the insured with cover for three years after termination of his policy. Although that sounds very generous at first sight, a second look, again, proves the cautiousness of insurers in this area: The amount of cover is limited to the aggregate limit of the last year of insurance. After the last year cover has been exhausted the insured has to live at his own peril. 